\title{
Acute Effects of Pulmonary Exposure to Zinc Oxide Nanoparticles on the Brain in vivo
}

\author{
Hsiao-Chi Chuang1,2,3, Yu-Ting Yang ${ }^{4}$, Hsin-Chang Chen ${ }^{5}$, Yaw-Huei Hwang ${ }^{4,6}$, Kuen-Yuh Wu ${ }^{4}$, \\ Ta-Fu Chen ${ }^{7}$, Chia-Ling Chen ${ }^{1}$, Ming-Kai Jhan ${ }^{8,9}$, Tsun-Jen Cheng ${ }^{4,5^{*}}$ \\ ${ }^{1}$ School of Respiratory Therapy, College of Medicine, Taipei Medical University, Taipei 11031, Taiwan \\ ${ }^{2}$ Cell Physiology and Molecular Image Research Center, Wan Fang Hospital, Taipei Medical University, Taipei 11696, \\ Taiwan \\ ${ }^{3}$ Division of Pulmonary Medicine, Department of Internal Medicine, Shuang Ho Hospital, Taipei Medical University, New \\ Taipei 23561, Taiwan \\ ${ }^{4}$ Institute of Occupational Medicine and Industrial Hygiene, College of Public Health, National Taiwan University, Taipei \\ 10617, Taiwan \\ ${ }^{5}$ Institute of Food Safety and Health, College of Public Health, National Taiwan University, Taipei 10617, Taiwan \\ ${ }^{6}$ Department of Public Health, College of Public Health, National Taiwan University, Taipei 10617, Taiwan \\ ${ }^{7}$ Department of Neurology, National Taiwan University Hospital, College of Medicine, National Taiwan University, \\ Taipei 10617, Taiwan \\ ${ }^{8}$ Graduate Institute of Medical Sciences, College of Medicine, Taipei Medical University, Taipei 11031, Taiwan \\ ${ }^{9}$ Department of Microbiology and Immunology, School of Medicine, College of Medicine, Taipei Medical University, \\ Taipei 11031, Taiwan
}

\begin{abstract}
Although the applications for zinc oxide nanoparticles (ZnONP) are continually increasing, the neurotoxicity of this material remains unclear. This study investigated the acute effects of pulmonary exposure to $\mathrm{ZnONP}$ on the brain in terms of behavioral changes, oxidative stress, inflammation, and tau and autophagy expressions using rat subjects. Based on the test subjects' performance in a Morris water maze and an elevated-plus maze, respectively, no major alterations occurred in spatial cognition or learning ability, or anxiety. Following exposure to $10 \mathrm{mg} \mathrm{kg}^{-1}$ of $\mathrm{ZnONP}$, we observed that the level of 8-hydroxy-2'-deoxyguanosine (8-OHdG)/dG significantly increased in the hippocampus, whereas those of interleukin (IL)-1 $\beta$ and IL-6 significantly decreased in the cerebellum and the cortex. Additionally, microglia were activated in the hippocampus. Tau protein expression was strong in the cerebellum and the hippocampus, but no significant expression of Beclin-1, light chain 3 (LC3) II/I, or ubiquitin was detected. Our results suggest that acute exposure to ZnONP induces oxidative stress, microglia activation, and tau protein expression in the brain, leading to neurotoxicity.
\end{abstract}

Keywords: Autophagy; Central nervous system; Elevated-plus maze; Morris water maze; Nanoparticle; Ubiquitin.

\section{INTRODUCTION}

Zinc oxide nanoparticles (ZnONP) are used in many commercial nanomaterials and food additives, and have been detected in ambient air and occupational environments (Fine et al., 1997; Grommes and Soehnlein, 2011). In the United States, the permissible exposure limit (PEL) for zinc oxide $(\mathrm{ZnO})$ in occupational environment is set to $5 \mathrm{mg} \mathrm{m}^{-3}$

\footnotetext{
* Corresponding author.

Tel: +886-2-33668090; Fax: +886-2-23957845

E-mail address: tcheng@ntu.edu.tw
}

of respirable particles (Gordon and Fine, 1993). Notably, pulmonary exposure of $\mathrm{ZnO}$ has been linked to adverse human health effects. For example, metal fume fever occurs after exposure to $\mathrm{ZnO}$ for a few hours (Kwon et al., 2014), and acquired tolerance occurs after repeated exposures (Fine et al., 2000). A study showed that zinc-hexachloroethane smoke caused lung fibrosis after exposure (Richards et al., 1989). Our previous reports showed cardiopulmonary effects caused by ZnONP exposure in vivo (Chuang et al., 2014; Pan et al., 2015; Chuang et al., 2017) and in vitro (Pan et al., 2014). However, neurotoxicity that occurs with pulmonary exposure of $\mathrm{ZnONP}$ remains unclear.

A clinical study observed that metal fume exposure contributes to neuropsychological disorders in welders, 
including a loss of balance, cognitive disorders, and Parkinsonism (Bowler et al., 2007). Clinical observations suggest that chronic exposure to metal fumes may be associated with the development of neurodegenerative diseases. Increasing numbers of studies have highlighted the possibility of neurotoxicity caused by nanoparticles (Sharma and Sharma, 2012; Mushtaq et al., 2015). ZnONP, for example, were indicated to regulate synaptic transmission in vitro (Zhao et al., 2009) and to disturb spatial cognition in vivo (Han et al., 2011). A recent study indicated that anxiogenic behavior of male Swiss mice could be associated with exposure of ZnONP by intraperitoneal injection (de Souza et al., 2018). Currently, three possible pathways are potentially involved in the influence of nanoparticles on the brain: (1) direct penetration of the blood-brain barrier (BBB), (2) translocation along the olfactory nerve, and (3) indirect effects from oxidative stress and inflammation. Due to the unique physicochemistry of $\mathrm{ZnONP}$, their neurotoxicity might not result from a single pathway. It was reported that ZnONP can reach the brain via the olfactory bulb-brain translocation pathway after exposure (Garcia and Kimbell, 2009; Kao et al., 2012). Also, ZnONP is able to interact with plasma and brain proteins and regulate rat blood and brain homogenates (Shim et al., 2014). Therefore, it is important to understand the neurotoxicity of the central nervous system (CNS) after pulmonary exposure of ZnONP.

Notably, inhaled nanoparticles are associated with oxidative-inflammatory reactions at sites of deposition (Oberdorster et al., 2009). Combustion-derived Zn has been linked to increase of oxidative DNA damage (Xiao et al., 2013; Shao et al., 2016; Shao et al., 2017). Oxidative stress is recognized to initiate neurodegenerative diseases, leading to loss of cognitive function (Calderon-Garciduenas et al., 2004). Inflammation is a critical response in the development of CNS abnormities. For example, proinflammatory cytokines, and excitatory amino acids and nitroxidative species may be associated with cognitive deficits and neurodegenerative diseases (Uttara et al., 2009). Activation of microglia was implicated in neuronal injury, which is associated with the occurrence of many neurodegenerative diseases and conditions (Carnevale et al., 2007; Dheen et al., 2007). The microglial response supports the potential of a common underlying neuroinflammatory mechanism, which is reprogrammed to a heightened proinflammatory phenotype (priming) to become deleterious in neurodegenerative diseases. Previous studies have reported that $\mathrm{ZnONP}$ caused microglia activation and neuron death (Sruthi and Mohanan, 2015; Sharma et al., 2017).

Tau proteins accumulated intraneuronally is believed as an important hallmark in the development of neurodegenerative diseases (Serrano-Pozo et al., 2011). Additionally, autophagy is able to play an essential degradative mechanism that remove tau from cells in brain. Together, oxidative-inflammatory responses and tau-cleaning mechanisms could be vital to regulating neurodegenerative diseases. The neurotoxic potential of $\mathrm{ZnONP}$ was recently investigated; however, their impacts on the CNS remain unclear. We hypothesized that inhaled ZnONP cause neurotoxicity on CNS. The objective of the present study was to investigate the effects of ZnONP on brain. We investigated behavioral alterations, oxidative stress and inflammation as well as tau, autophagy and ubiquitin expressions after acute pulmonary exposure.

\section{METHODS}

\section{Particles and Reagent Sources}

$\mathrm{ZnONP}$ at $50 \mathrm{~nm}$ in average diameter and $10.8 \mathrm{~m}^{2} \mathrm{~g}^{-1}$ in surface area were obtained from Sigma-Aldrich (CAS No. 1314-13-2; St. Louis, MO, USA). Their physicochemical characteristics were previously reported (Chuang et al., 2014). All other reagents were obtained from Sigma-Aldrich (St. Louis, MO, USA), unless explicitly stated otherwise.

\section{Physical Characterization of Znonp}

We dispersed ZnONP in phosphate-buffered saline (PBS) supplemented with $5 \%$ bovine serum albumin (BSA) at final concentrations of 5 and $10 \mathrm{mg} \mathrm{mL}^{-1}$ with $30 \mathrm{~min}$ of sonication. Serum protein was reported to well disperse nanoparticles when suspended in solution (Chuang et al., 2014). Hydrodynamic diameters were determined using a Zetasizer 3000HS (Malvern Instruments, Worcestershire, UK). ZnONP solutions in PBS with $5 \%$ BSA were then air-dried on grids followed by adherence to carbon adhesive tabs on aluminum scanning electron microscopic (SEM) stubs. An FEI Ultra High Resolution Field Emission-SEM (FE-SEM; Nova NanoSEM 230; Hillsboro, OR, USA) was used to investigate the morphology of $\mathrm{ZnONP}$ at 5 and $10 \mathrm{mg} \mathrm{mL}^{-1}$.

\section{Animals}

Seven-week-old male Sprague Dawley (SD) rats were obtained from the National Laboratory Animal Center (Taipei, Taiwan). Rats were housed in plastic cages under a $22 \pm 2^{\circ} \mathrm{C}$ temperature and $55 \pm 10 \%$ relative humidity in a 12/12-h light/dark cycle. All animal experiments complied with protocols of the Institutional Animal Care and Use Committee (IACUC) at National Taiwan University (Taipei, Taiwan; IACUC approval No. 20150233).

\section{Experimental Design}

The experimental design is shown in Fig. 1. On Day 0, rats were given intratracheal (IT) instillation of 0 (vehicle control), 5 , and $10 \mathrm{mg} \mathrm{kg}^{-1}$ body weight of $\mathrm{ZnONP}$ in $200 \mu \mathrm{L}$ PBS (with 5\% BSA) per rat under light anesthesia (2\% isoflurane) using a rodent anesthesia machine ( $n=15$ per treatment; Northern Vaporisers Ltd., Skipton, UK). On Day 1, 5 rats each treatment were randomly selected for elevated-plus maze followed by euthanasia (by $\mathrm{CO}_{2}$ ) after the experiment. The samples were collected for biochemical analyses. Rats from the biochemical analyses were immediately decapitated. The cerebellum, cortex, and hippocampus of each rat were obtained, frozen in liquid nitrogen, and stored at $-80^{\circ} \mathrm{C}$ for biochemical and metal analyses. The rest of 10 rats were performed a Morris water maze (MWM; $n=10$ per treatment) on Days 8-13. On Day 13, the elevated-plus maze was conducted followed by euthanasia after the experiment. The behavior examination was conducted in an animal behavior room, which is a soundproof room with controlled environment (e.g., light, temperature and humidity). Rats for histology 


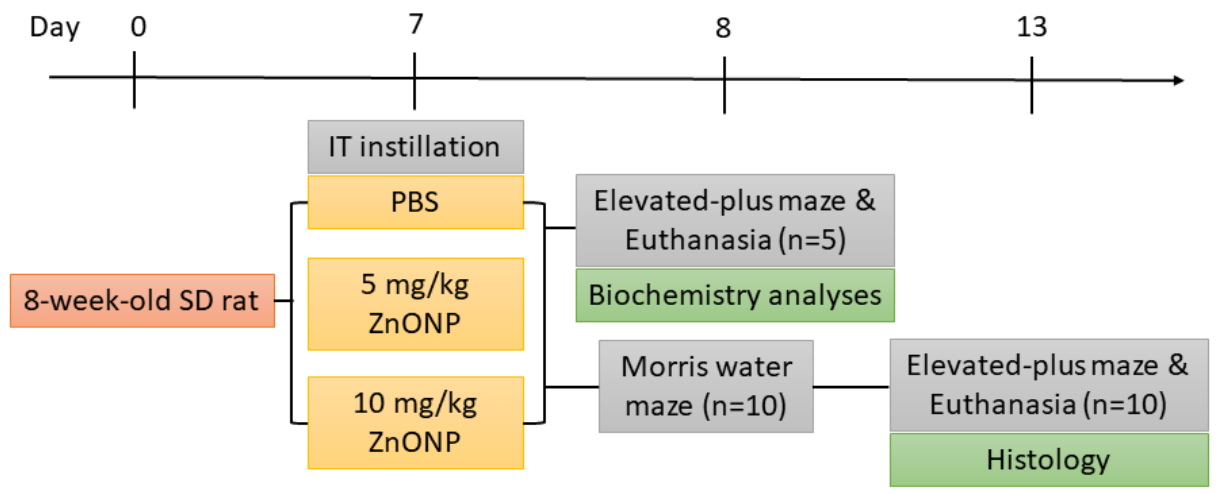

Fig. 1. Overview of the experimental design for zinc oxide nanoparticle (ZnONP) exposure in SD rats. Rats were exposed to 0 (PBS vehicle control with $5 \%$ BSA), 5, and $10 \mathrm{mg} \mathrm{kg}^{-1} \mathrm{ZnONP}$ via intratracheal (IT) instillation. Elevated-plus maze and Morris water maze was conducted for observe behavior changes by ZnONP. Cerebellum, cortex and hippocampus were collected for biochemical analyses and histology.

were transcardially perfused with $30 \mathrm{~mL}$ saline plus a $4 \%$ paraformaldehyde (PFA) solution in $0.1 \mathrm{M}$ phosphate buffer (pH 7.4) after the experiment. Brains were quickly removed from the skull and immersed overnight in $10 \%$ formaldehyde at $4{ }^{\circ} \mathrm{C}$ for pathological observation. The concentrations used for $\mathrm{ZnONP}$ administration was selected to induce lung inflammation after exposure (Juan, 2011). The ZnONP doses were relevant for human exposure for occupational exposure scenarios according to a previous method (Vietti et al., 2013; Rovira et al., 2014): the alveolar surface area, breathing frequency (30 times $\mathrm{min}^{-1}$ ), lung deposition rate $(30 \%)$, minute ventilation of $20 \mathrm{~L} \mathrm{~min}^{-1}$, and the recommended $\mathrm{ZnO}$ standard of $5 \mathrm{mg} \mathrm{m}^{-3}$ (Fine et al., 1997). The humanequivalent mass concentration $\left(7.2 \mathrm{mg} \mathrm{day}^{-1}\right)$ would be achieved in 36 days with $5 \mathrm{mg} \mathrm{kg}^{-1}$ and in 71 days with $10 \mathrm{mg} \mathrm{kg}^{-1}$.

\section{Morris Water Maze (MWM)}

The MWM was used to examine spatial learning, according to our previous report (Chen et al., 2010). Briefly, the MWM consisted of a circular pool with a diameter of $120 \mathrm{~cm}$ and a height of $60 \mathrm{~cm}$. A white platform ( $9 \mathrm{~cm}$ with rough surface) was submerged $1 \mathrm{~cm}$ below the water surface. The pool was filled with water containing milk and the water temperature was kept at $25^{\circ} \mathrm{C}$. The pool was divided into four equal quadrants, and each quadrant was marked with a different visual cue. There were two phases during the study period: an acquisition phase (Days 1-4) and a probe trial phase (Day 5) for examining spatial learning and memory ability, respectively. The reference for the MWM has been described previously (da Silva et al., 2018). The endogenous reference such as recording camera apparatus was fixed in the experimental room during the study. The researcher was stood on the same place throughout the training and experiment. All data were recorded using a video camera-based system (EthoVision 3.1; Noldus, Wageningen, Netherlands).

\section{Elevated-plus Maze}

An elevated-plus maze was used to evaluate anxiety, according to a previous report (Walf and Frye, 2007). The elevated-plus maze consisted of two open arms, two enclosed arms, and a central platform made of black Plexiglas. Times spent in the open and closed arms and the number of entries made into each arm were recorded with a video camera (EthoVision 3.1; Noldus). The level of anxiety was measured by the variables of the time spent and the percentages of entries in the open and closed arms. Anxiety index (Anxiety index $=1-[([$ open arm time/test duration $]+$ [open arm entries/total number of entries])/2]) was calculated according to a previous report (da Costa Estrela et al., 2015).

\section{Oxidative Stress}

WelPre DNA kit (Welgene Biotech, Taipei, Taiwan) was used to extract DNA from brain tissue, according to the manufacturer's instructions. A NanoVue Spectrophotometer (Biochrom, Holliston, MA, USA) was used to determine DNA concentrations and purity. Samples were spiked with $20 \mu \mathrm{L}$ of ${ }^{15} \mathrm{~N}_{5}-8$-hydroxy-2'-deoxyguanosine $\left({ }^{15} \mathrm{~N}_{5}-8-\mathrm{OHdG}\right.$; $25 \mathrm{ng} \mathrm{mL} \mathrm{m}^{-1}$, 99\% purity; Cambridge Isotope Laboratories, Andover, MA, USA) and ${ }^{13} \mathrm{C}_{3}-8-\mathrm{NG}\left(25 \mathrm{ng} \mathrm{mL}^{-1}\right)$, and these served as the internal standards. Samples were vortexed for solid-phase extraction (SPE; Sep-Pak $\mathrm{C}_{18}$ cartridge; Waters, Milford, MA, USA). Details of DNA isolation and preparation were previously reported (Li et al., 2005; Wu et al., 2016). Levels of $8-\mathrm{NO}_{2}$ Gua, $8-\mathrm{OHdG},{ }^{15} \mathrm{~N}_{5}-8-\mathrm{OHdG}$, and ${ }^{13} \mathrm{C}_{3}-8-\mathrm{NG}$ were determined using liquid chromatography-tandem mass spectrometry (LC-MS/MS; TSQ Quantum ${ }^{\mathrm{TM}}$ Access MAX; Thermo Scientific, MA, USA). Levels of deoxyguanosine (dG) and guanine (Gua) were determined using highperformance liquid chromatography (HPLC) with UV detection (HPLC-UV; AS950 and PU980; Jasco, Easton, MD, USA). LC-MS/MS and HPLC-UV data were analyzed by Xcalibur 2.2 (Thermo Fisher Scientific) and the Scientific Information Service Corporation chromatography data system (Scientific Information Service Corporation, Taipei, Taiwan), respectively. Spectra of the LC-MS/MS and HPLC-UV analyses are given in Supplementary Information Figs. S1 and S2.

\section{Brain Inflammation}

A Bio-Plex rat cytokine assay (Bio-Rad, Hercules, CA, USA) was used in this study. Levels of interleukin (IL)-1 $\alpha$, 
IL-1 $\beta$, IL-6, and tumor necrosis factor (TNF)- $\alpha$ in brain tissues were acquired with a Bio-Plex 200 system with Luminex (Bio-Rad) and analyzed using Bio-Plex Manager (Bio-Rad).

\section{Immunohistochemistry}

For immunohistochemistry, the brain tissues were embedded in paraffin and sliced at a thickness of $5 \mu \mathrm{m}$ after deparaffinization and antigen retrieval for the section. Tissue was stained with activated microglial marker Iba-1 (GeneTex, San Antonio, TX, USA). DAPI was used for nuclear staining. For neuron detection, Nissl staining buffer (1\% Cresyl Violet, $1 \%$ Glacial Acetic Acid in $\mathrm{ddH}_{2} \mathrm{O}$ ) was used to measure Nissl bodies in the cytoplasm of neurons. To detect brain lesions, tissue sections were visualized by a fluorescent microscope (EVOS FL imaging system; Thermo Fisher Scientific, Inc., Waltham, MA, USA). Images were taken and stitched into large image by automated microscopy (TissueFAXS; TissueGnostics GmbH, Vienna, Austria).

\section{Western Blot Analysis}

Tissue lysates were subjected to sodium dodecyl sulfatepolyacrylamide gel electrophoresis (SDS-PAGE) followed by electrotransfer onto polyvinylidene difluoride (PVDF) membranes (Millipore, Darmstadt, Germany). The primary antibodies for Beclin 1 (1:1000), light chain 3 (LC3; 1:1000), tau (1:1000), ubiquitin $(1: 1000)$, and $\beta$-actin $(1: 1000)$ were obtained from Cell Signaling (Danvers, MA, USA). Anti-rabbit (1:2000) and anti-mouse (1:2000) horseradish peroxidase (HRP)-conjugated secondary antibodies were obtained from Chemicon International (MA, USA) and Merck Millipore (MA, USA), respectively. After blocking with 5\% skim milk in PBST, an HRP-labeled secondary antibody was incubated and washed with TBST. Enhanced chemiluminescence (ECL) Western blotting reagents were used. Proteins were visualized through incubation with the colorimetric substrates NBT and BCIP. Quantitative data were obtained using Image-Pro vers. 4 (Media Cybernetics, MD, USA) for Windows. All data were adjusted to the control (multiples of change of the control). Details of the Western blot analysis were previously reported (Chen et al., 2004).

\section{Zn in Brain Tissues}

Inductively coupled plasma mass spectrometry (ICP-MS; Model 7500c; Agilent, USA) was used to determine $\mathrm{Zn}$ concentrations in cerebellum and cortex. Samples were digested using concentrated nitric acid (Fisher Scientific, USA) in a MARS 5 microwave system (CEM, USA) in CEM advanced Teflon-lined composite vessels (Jones et al., 2006). Nitric acid and deionized water (> $18 \mathrm{M} \Omega$ ) were added to the samples to a final concentration of $5 \%$ nitric acid. Nitric acid and deionized water blanks were used to detect contamination during the analytical process.

\section{Histology}

Brains were excised and then fixed with $10 \%$ neutral buffered formalin. Samples were embedded in paraffin, sectioned, and stained with hematoxylin and eosin (H\&E). Histology was blindly examined under light microscopy.

\section{Statistical Analysis}

One-way analysis of variance (ANOVA) with Fisher's least significant difference post hoc test was used for comparisons among multiple values. Statistical analyses were performed using GraphPad vers. 5 for Microsoft Windows (La Jolla, CA, USA). The level of significance was set to $p$ $<0.05$.

\section{RESULTS AND DISCUSSION}

\section{Physical Characterization of Znonp}

To study the effects of ZnONP on the CNS in vivo, we first investigated the physical modification of $\mathrm{ZnONP}$ when suspended in the BSA-containing PBS vehicle for pulmonary exposure. Fig. 2 shows the physical characterization of $\mathrm{ZnONP}$ at 5 and $10 \mathrm{mg} \mathrm{mL}^{-1}$ used in this study. There was no significant difference in the hydrodynamic diameters of $\mathrm{ZnONP}$ at 5 and $10 \mathrm{mg} \mathrm{mL}^{-1}$, which were $271 \pm 23$ and 257 $\pm 14 \mathrm{~nm}$, respectively. The results indicate that the $\mathrm{ZnONP}$ was well suspended with some spherical aggregation in the solution, even at the highest mass concentration. ZnONP suspended in PBS with 5\% BSA were mainly spherical particles with some aggregation. BSA is commonly used in nanoparticle testing because it is recognized as a good surfactant to adequately disperse nanoparticles when suspended in biological solutions (Cho et al., 2012).

Notably, although BSA is able to disperse ZnONP in PBS, size fractions remained between $257\left(5 \mathrm{mg} \mathrm{mL}^{-1}\right)$ and $271 \mathrm{~nm}\left(10 \mathrm{mg} \mathrm{mL}^{-1}\right)$. On the other hand, the possibility of $\mathrm{ZnONP}$ bypassing the BBB is relatively low due to the large size fractions. The olfactory bulb is also considered a route for nanoparticle translocation into the brain. In the present study, IT instillation was used for in vivo exposure, thus ZnONP entering the brain via the olfactory bulb was insignificant. Lung-to-brain inflammation may have been one of the pathways of $\mathrm{ZnONP}$-induced neurotoxicity in the present study. In the present study, the rats were received a single administration of $\mathrm{ZnONP}$. The mass concentrations administrated to rats were relevant to occupational exposure scenarios in humans (Rovira et al., 2014), considering the alveolar surface area, breathing frequency, and lung deposition rate. Furthermore, workplace conditions, such as working day ventilation and PEL for $\mathrm{ZnO}\left(5 \mathrm{mg} \mathrm{m}^{-3}\right)$, were considered. The exposure concentration was chosen to induce significant oxidative stress and inflammation after pulmonary exposure. Additionally, sex hormones have been associated with neurodegenerative disease (Vegeto et al., 2008; Villa et al., 2016). In the present study, male rats were used to control the effects of estrogens on the development of neurodegenerative disease after $\mathrm{ZnONP}$ exposure. The acute effects of $\mathrm{ZnONP}$ were investigated after 1 day and 7 days of exposure.

\section{Behavioral Observations}

Behavioral alterations caused by ZnONP exposure were firstly evaluated, including spatial orientation and memory by the MWM and anxiety by the elevated-plus maze. Fig. 3 shows the acquisition phase (Days 1-4) and probe trial (Day 5) using the MWM to respectively examine spatial 

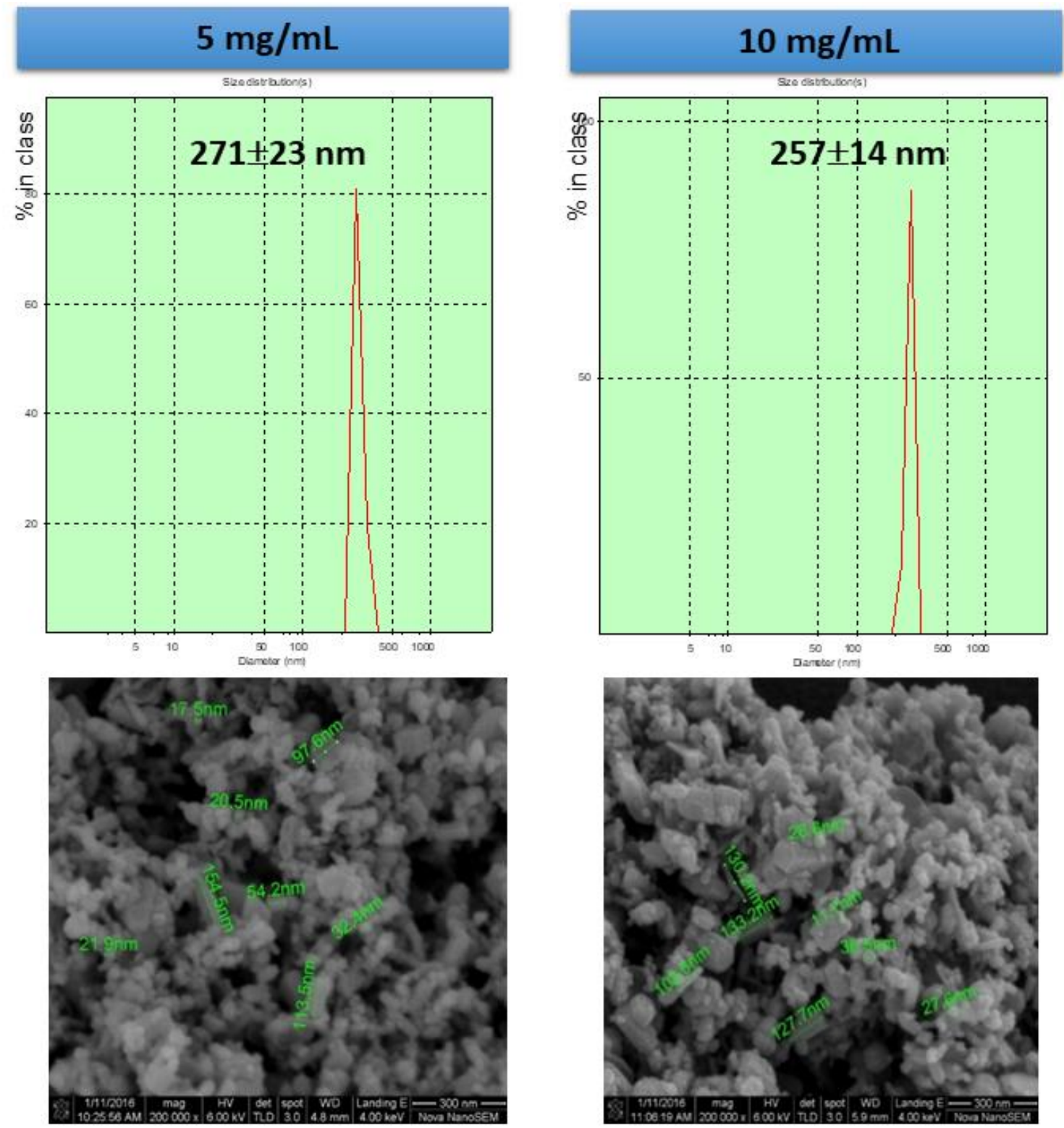

Fig. 2. Physical analyses of zinc oxide nanoparticles (ZnONP) when dispersed in 5\% BSA in PBS. The hydrodynamic diameters of $\mathrm{ZnONP}$ at 5 and $10 \mathrm{mg} \mathrm{mL}^{-1}$ were $271 \pm 23$ and $257 \pm 14 \mathrm{~nm}$, respectively. The ZnONP mainly presented as spherical aggregates.

learning and memory ability. There were no significant differences in the escape latency or distance moved among the control, and 5 and $10 \mathrm{mg} \mathrm{kg}^{-1} \mathrm{ZnONP}$ exposure groups. For the probe trial, there were no significant differences in the number of times crossing the target quadrant, time in the target quadrant, or the swimming velocity among the control, and 5 and $10 \mathrm{mg} \mathrm{kg}^{-1} \mathrm{ZnONP}$ exposure groups. Fig. 4 shows the levels of anxiety determined by the elevated-plus maze on Days 1 and 5 after exposure in the control, and 5 and $10 \mathrm{mg} \mathrm{kg}^{-1} \mathrm{ZnONP}$ exposure groups. There were no significant differences in the anxiety index after ZnONP exposure on Days 1 and 5. Additionally, there were no significant differences in the open-arm time, open-arm entries (\%), closedarm time or closed-arm entries (\%) after ZnONP exposure on Days 1 and 5 (Fig. S3).
We observed acute exposure of ZnONP did not occur significant alteration in behavior in the rats. Our observations are inconsistent with some previous studies of $\mathrm{ZnONP}$ exposure. For example, one reported showed that $\mathrm{ZnONP}$ impaired the spatial cognitive capability of Wistar rats after 8 weeks of exposure (Han et al., 2011). Swiss mice exposed to $5.6 \mathrm{mg} \mathrm{kg}^{-1}$ of ZnONP 8 times (every other day) damaged spatial cognition (Xie et al., 2012). Previous studies showed that exposure to $\mathrm{ZnONP}$ induced anxiety-like behaviors in rats after an intraperitoneal (i.p.) injection of 5-20 mg ZnONP kg-1 (Torabi et al., 2013). Different observations in spatial cognition, memory ability, and anxiety in previous reports could have resulted from distinct exposure durations (single and repeated) and administration routes (IT and i.p.). A reported showed that $\mathrm{Zn}$ may have the anxiogenic effects 


\section{Acquisition phase (Days 1-4)}

Escape latency

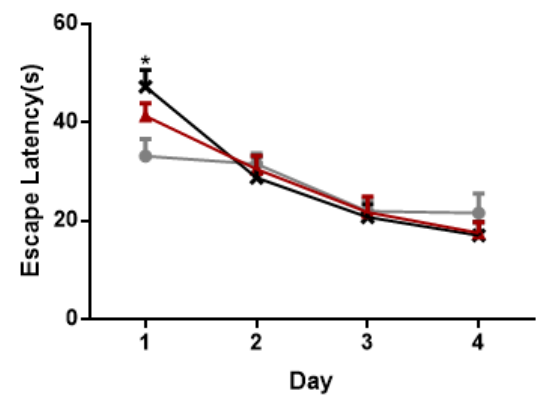

Probe trial (Day 5)

Cross numbers in target quadrant

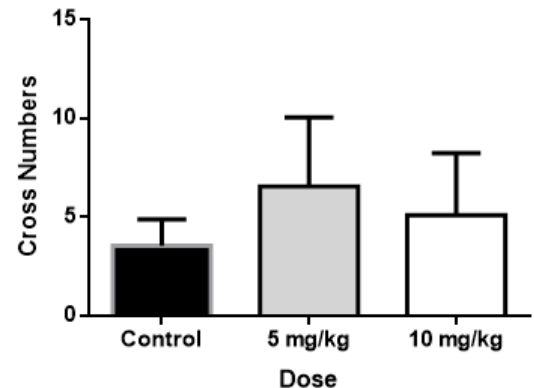

$\rightarrow$ Control

* $5 \mathrm{mg} / \mathrm{kg}$

$+10 \mathrm{mg} / \mathrm{kg}$

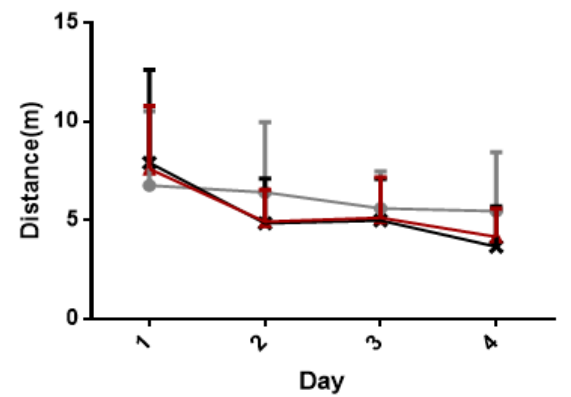

Time in target quadrant

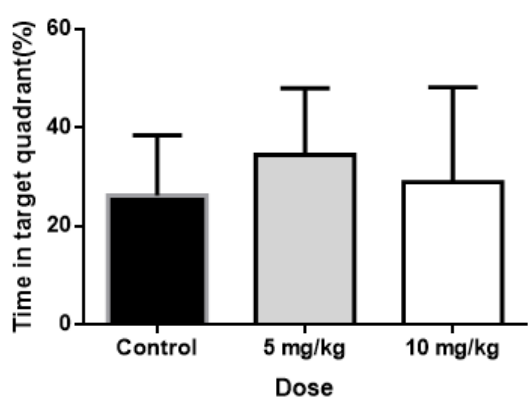

Swim Velocity

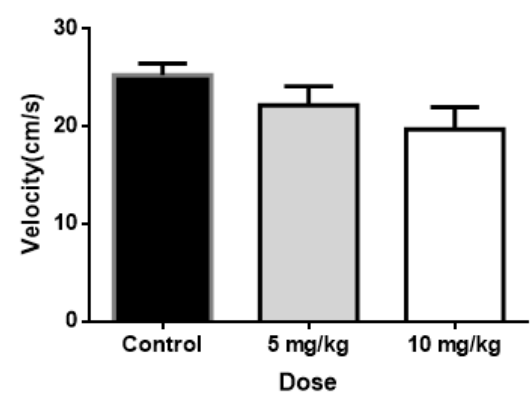

Fig. 3. Morris water maze for examination of spatial learning (acquisition phase, Days 1-4) and memory ability (probe trial, Day 5). There were no significant differences in the escape latency or distance, the number of times crossing the target quadrant, the time in the target quadrant, of the swimming velocity after 5 and $10 \mathrm{mg} \mathrm{kg}^{-1}$ of $\mathrm{ZnONP}$ exposure.

Day 1

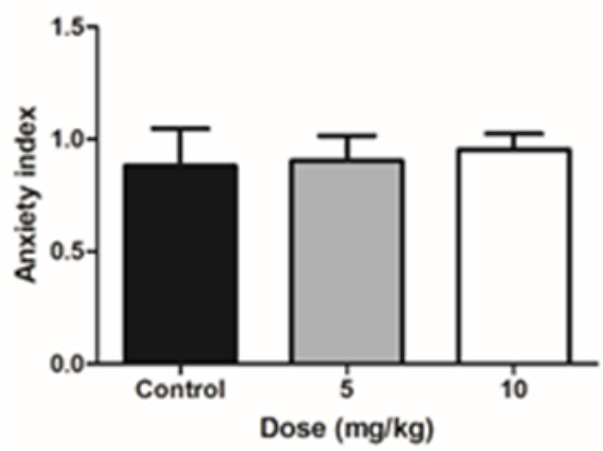

$\underline{\text { Day } 5}$

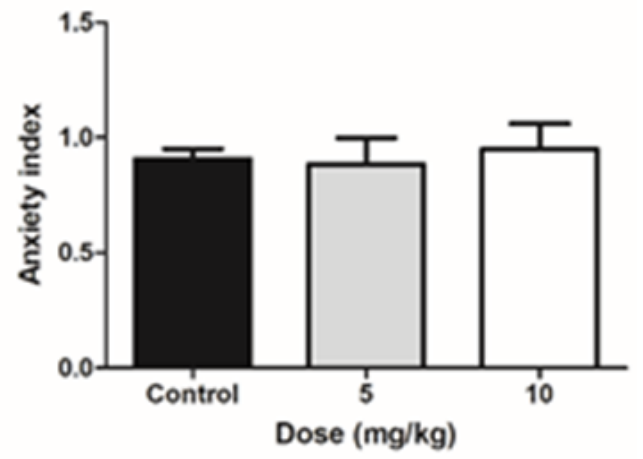

Fig. 4. The elevated-plus maze for examination of anxiety on Days 1 and 5 after exposure to control, and 5 and $10 \mathrm{mg} \mathrm{kg}^{-1}$ zinc oxide nanoparticles ( $\mathrm{ZnONP})$. There were no significant differences in the anxiety index after ZnONP exposure on Days 1 and 5 .

after administration (Samardzic et al., 2013; de Souza et al., 2018), which could explain the results observed in the present study. The percent of time spent in the open arms decreased with exposure to $10 \mathrm{mg} \mathrm{kg}^{-1} \mathrm{ZnONP}$, which is similar as a previous study (de Souza et al., 2018). The insignificant results may be due to the small sample size used for behavior observation.

\section{Brain Oxidative Stress and Inflammation}

To study early-phase responses to acute ZnONP exposure, the cerebellum, cortex, and hippocampus of rat brains were examined. Fig. 5 shows brain oxidative stress and inflammation levels in the cerebellum, cortex, and hippocampus after $\mathrm{ZnONP}$ exposure. Levels of $8-\mathrm{OHdG} / \mathrm{dG}$ were significant increased by $10 \mathrm{mg} \mathrm{kg}^{-1}$ of $\mathrm{ZnONP}$ exposure in the hippocampus ( $p<$ 0.05; Fig. 5(a)). However, there were no significant differences in $8-\mathrm{NO}_{2} \mathrm{Gua} / \mathrm{Gua}$ levels in the cerebellum, cortex, or hippocampus after ZnONP exposure. These results suggest that the hippocampus may be sensitive to reactive oxygen species (ROS) generated by exposure to high levels of $\mathrm{ZnONP}$. 
The hippocampus plays an important role in cognition and memory functions. It depends on synaptic transmission properties which mainly refer to neuronal network and synaptic functions (Min et al., 2009). An imbalance of cytokines and ROS may directly cause neuronal injuries, leading to modifications of the volume of the hippocampus or disturbances in the transmitter system (Jayatissa et al., 2008). Although we observed an increase in oxidative stress in the hippocampus, subsequent impairment of cognition and memory functions was not observed in the present study.

Brain inflammation caused by $\mathrm{ZnONP}$ in mice was previously observed (Tian et al., 2015; Ansar et al., 2017). However, responses of different areas of the brain to $\mathrm{ZnONP}$ exposure remain unclear. We observed that IL- $1 \beta$ and IL- 6 significantly decreased in the cerebellum and cortex after exposure to $10 \mathrm{mg} \mathrm{kg}^{-1} \mathrm{ZnONP}(p<0.05$; Fig. 5(b)). There were no significant differences in IL- $1 \alpha$ and TNF- $\alpha$ in the cerebellum, cortex, and hippocampus after $\mathrm{ZnONP}$ exposure. The cerebellum is involved in motor control, cognitive function, and fear and pleasure responses (Wolf et al., 2009), whereas the cortex plays roles in memory, attention, cognition, and consciousness (Cabeza et al., 2008). Significant reductions in IL- $1 \beta$ and IL- 6 observed in the present study could have been due to anti-inflammatory responses in the cerebellum and cortex. The anti-inflammatory responses could associate with the behavioral results.

\section{Neuron Loss and Iba-1 Stain}

Fig. 6 shows results of Nissl and Iba-1 stain in the hippocampus after exposure to the 5 and $10 \mathrm{mg} \mathrm{kg}^{-1} \mathrm{ZnONP}$. There were no significant changes of neuron lost (by Nissl stain) observed in hippocampus after $\mathrm{ZnONP}$ exposure. We (a)

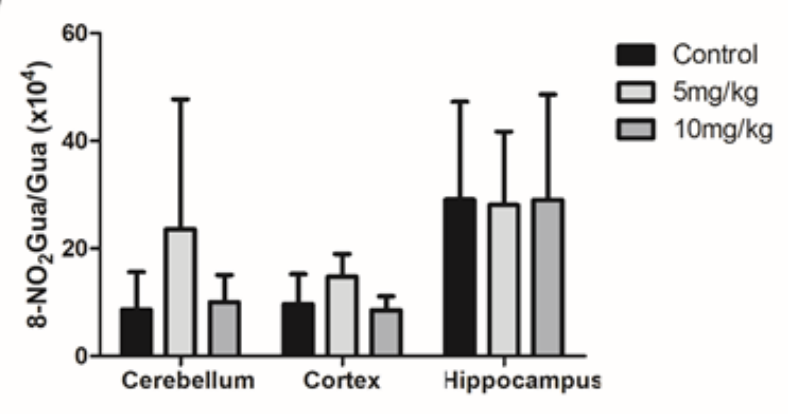

(b)
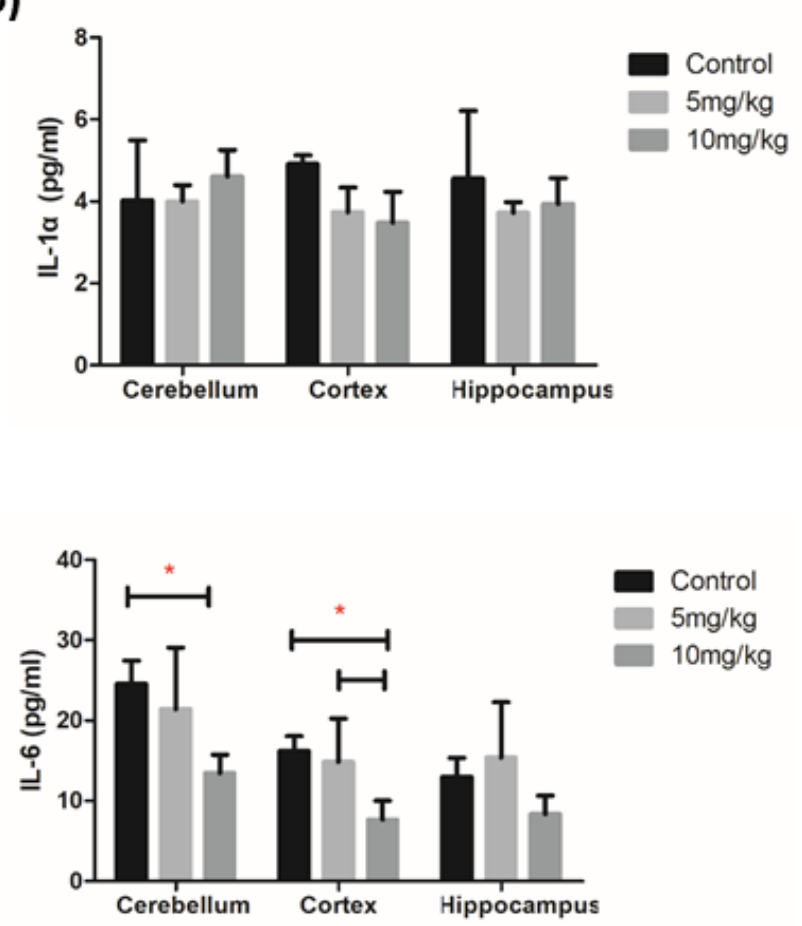
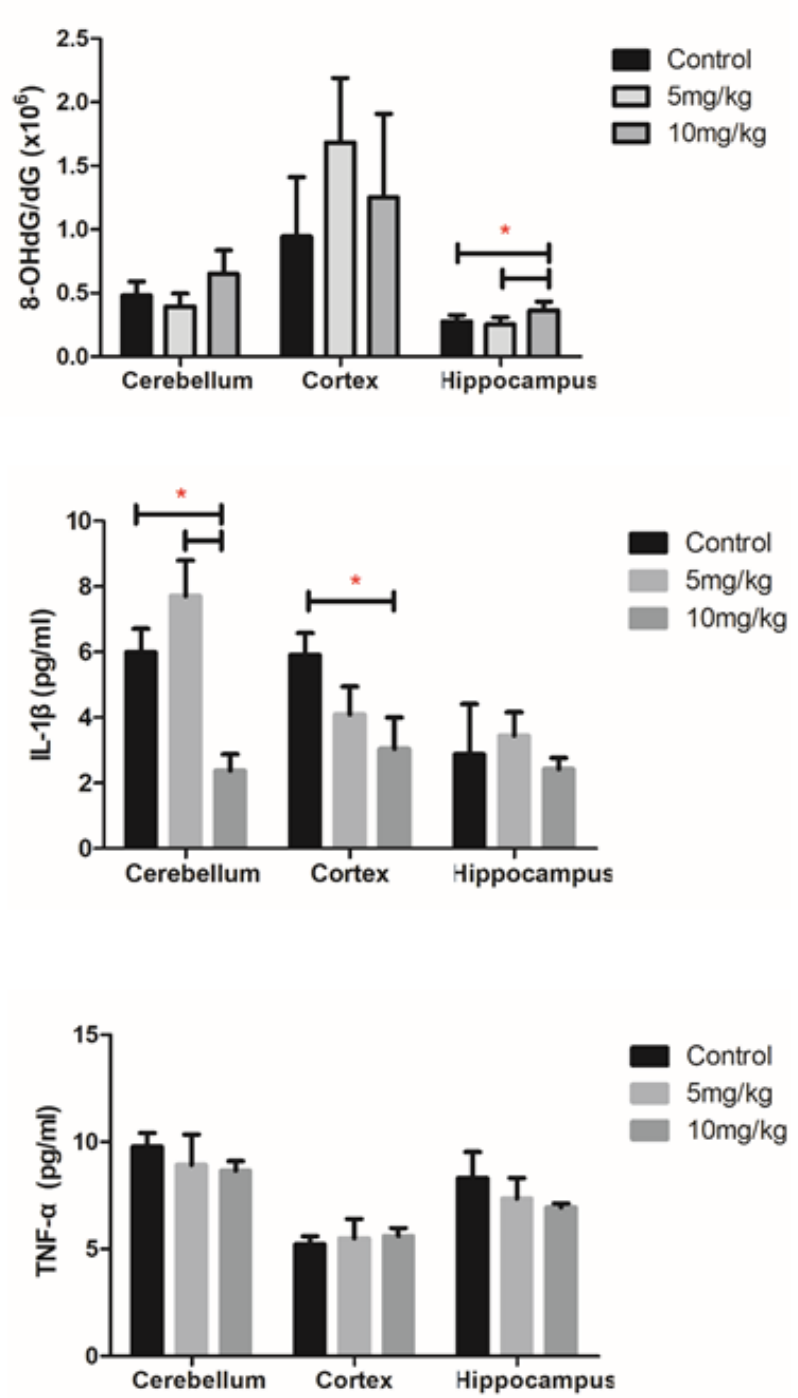

Fig. 5. (a) Levels of 8-hydroxy-2'-deoxyguanosine (8-OHdG)/dG and $8-\mathrm{NO}_{2} \mathrm{Gua} /$ guanine (Gua) in the cerebellum, cortex, and hippocampus after zinc oxide nanoparticle ( $\mathrm{ZnONP}$ ) exposure. 8-OHdG/Dg in the hippocampus significantly increased with exposure to $10 \mathrm{mg} \mathrm{kg}^{-1} \mathrm{ZnONP}$ ( $p<0.05$ ). (b) Interleukin (IL)-1 $\alpha$, IL-1 $\beta$, IL-6, and tumor necrosis factor (TNF)- $\alpha$ in the cerebellum, cortex, and hippocampus after zinc oxide nanoparticle (ZnONP) exposure. IL-1 $\beta$ and IL-6 significantly decreased in the cerebellum and cortex after exposure to $10 \mathrm{mg} \mathrm{kg}^{-1} \mathrm{ZnONP}(p<0.05)$. $* p<0.05$. 

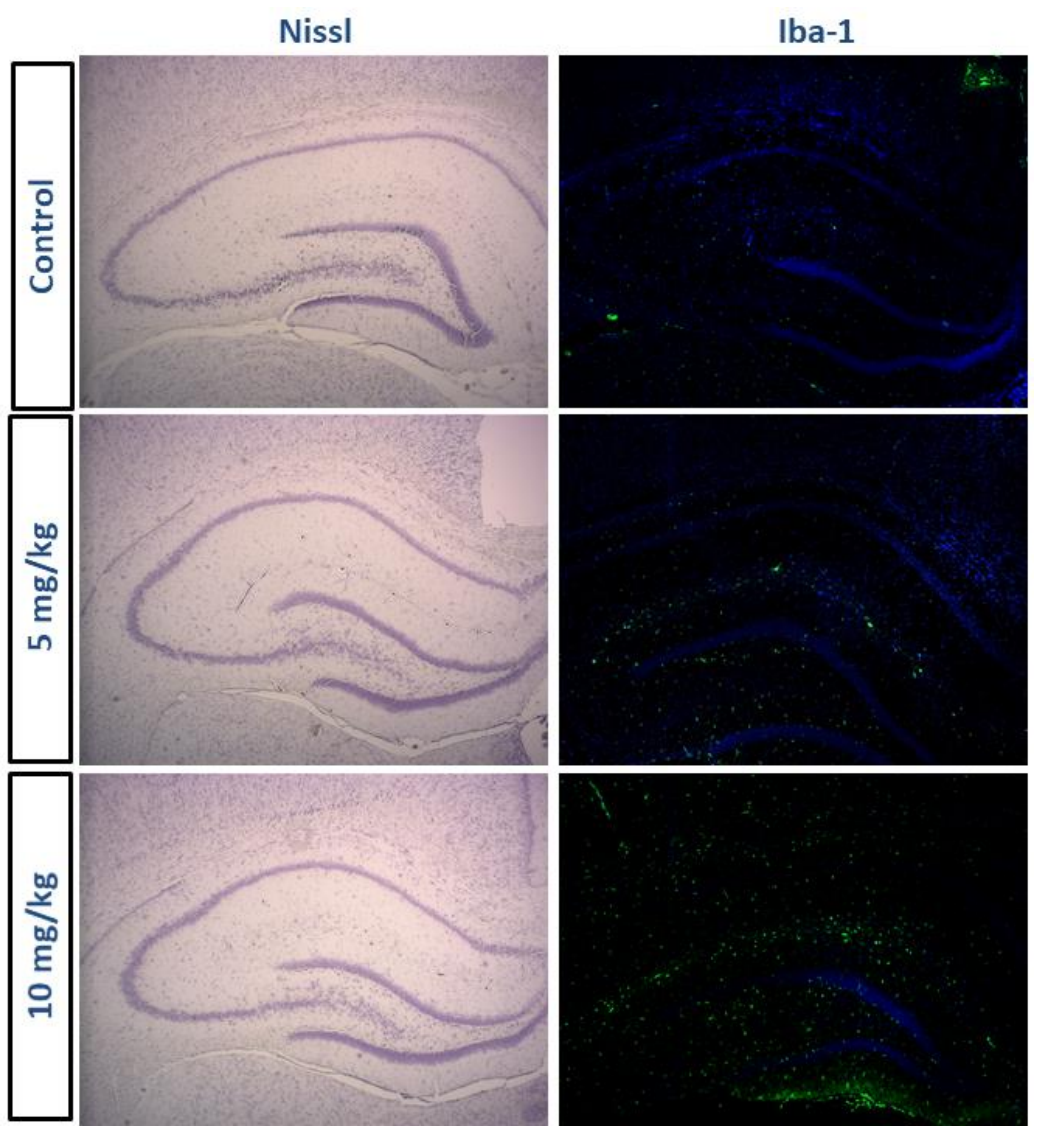

Fig. 6. Nissl stain and Iba-1 signals in the hippocampus of control, 5 and $10 \mathrm{mg} \mathrm{kg}^{-1}$ exposure of ZnONP for 7 days $(\times 40)$. We observed that significant microglial activation in the hippocampus occurred after ZnONP exposure at $10 \mathrm{mg} \mathrm{kg}^{-1}$.

observed significant expression of Iba-1 in hippocampus after exposure of $10 \mathrm{mg} \mathrm{kg}^{-1} \mathrm{ZnONP}$ when compared with the control. Our observation was in line with a previous report that ambient particles caused microglial activation, oxidative stress, neuroinflammation, and impaired neurogenesis in various brain regions such as the hippocampal subgranular zone and subventricular zone (Costa et al., 2015). Microglia play an important role in maintaining brain functions, as they are resident innate immune cells that act as sentinels to survey the central nervous system environment (Hickman et al., 2013). Notably, microglia activation plays dual roles in regulation of inflammatory responses (Tang and Le, 2016). Microglia respond to a vast repertoire of stimuli, including cellular damage, environmental stress, and pathogens (Block et al., 2007). Exacerbated and unregulated microglial proinflammatory responses are related to neuropathology and CNS diseases (Block et al., 2007), which are also linked to microglial priming (Perry and Holmes, 2014). A previous report showed that gold nanoparticle inhibited inflammatory reaction by microglia (Park et al., 2019). Therefore, further investigation is required to confirm the observation.

\section{Beclin-1, LC3, Tau, and Ubiquitin Expression in Brain}

Alteration in inflammation in the cerebellum and cortex were found after exposure to $10 \mathrm{mg} \mathrm{kg}^{-1} \mathrm{ZnONP}$. Therefore, rats exposed to $10 \mathrm{mg} \mathrm{kg}^{-1} \mathrm{ZnONP}$ were used for further investigation of Beclin-1, LC3 II (conjugated LC3), tau, and ubiquitin in the hippocampus, cerebellum, and cortex (Fig. 7). There were no significant alterations in Beclin-1 or the LC3 II/I ratio in the cerebellum, cortex, and hippocampus with ZnONP exposure compared to the control. We observed

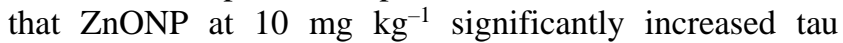
expressions in the cerebellum and hippocampus compared to the control $(p<0.05)$. There was no significant change in the expression of ubiquitin in the cerebellum, cortex, and hippocampus after control and $10 \mathrm{mg} \mathrm{kg}^{-1}$ of $\mathrm{ZnONP}$ exposure.

Tau overexpression in neuroblastoma cells can lead to tau aggregation and the appearance of smaller proteolytic fragments (Chesser et al., 2013). Tau overexpression in the brain may lead to tau accumulation, but there are some mechanisms that can clean tau from healthy brains. Degradative mechanisms, such as autophagy, remove tau aggregates from cells (Johansen and Lamark, 2011; Chesser et al., 2013). Previous studies have indicated autophagy regulation by ZnONP in vitro (Yu et al., 2013; Arakha et al., 2017; Bai et al., 2017). However, we observed no significant alterations in Beclin-1 or LC3 II expressions in brain sections. The results suggest that $\mathrm{ZnONP}$ exposure inactivated autophagy in the brain. There was no significant neuron loss of brain by ZnONP exposure. Autophagy inactivation and loss of basal autophagy could result in tau accumulation (Levine and Kroemer, 2008). A study showed that ZnONP could be an anti-glycation agent inhibiting AGE formation as well as protecting the protein structure from oxidation 

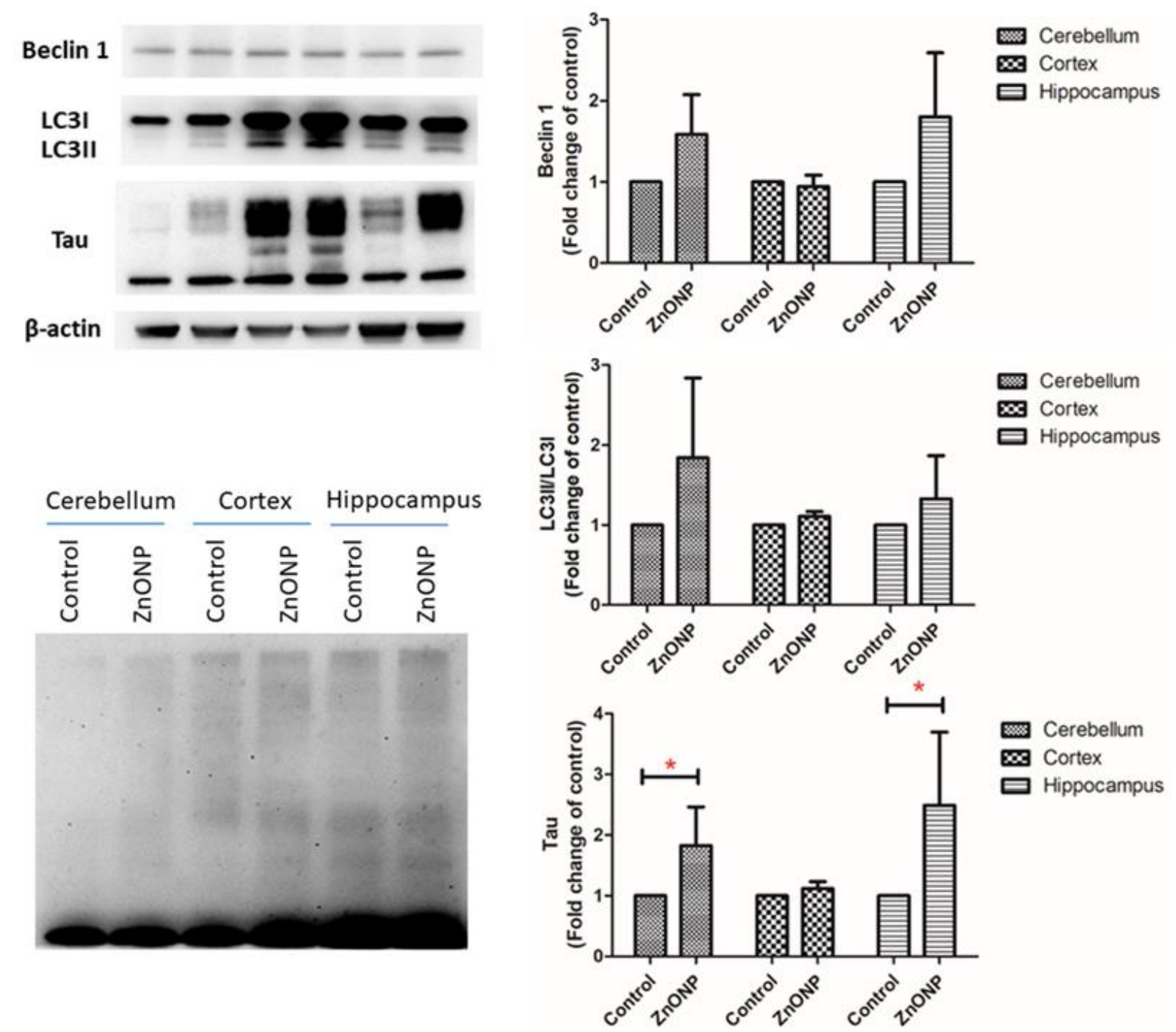

Fig. 7. Expressions of Beclin-1, light chain 3 (LC3) II/I ratio, tau, and ubiquitin in the cerebellum, cortex, and hippocampus after control and $10 \mathrm{mg} \mathrm{kg}^{-1}$ of zinc oxide nanoparticle ( $\mathrm{ZnONP}$ ) exposure. Levels of tau significantly increased after exposure to ZnONP in the cerebellum and hippocampus compared to the control $(p<0.05)$. $* p<0.05$.

(Ashraf et al., 2018). It suggests that low levels of ZnONP may have neuroprotective effects, inhibiting protein oxidative and activating autophagy. However, high concentrations of $\mathrm{ZnONP}$ could cause autophagy inactivation, leading to the formation of tau aggregates in the brain.

\section{Zn in the Brain}

$\mathrm{Zn}$ is considered a toxic element for lung toxicity (Adamson et al., 2000); however, the effects of ZnONP in brain remain unclear. The CNS is a sensitive site to interact with ions in physiological and pathological conditions (Chu and Xiong, 2012). Zinc ions, for example, are known to deteriorate the CNS during development. Zinc ions are able to leach from $\mathrm{ZnONP}$ and then diffuse to cells or organs, whereas the remaining $\mathrm{ZnONP}$ are able to continually release zinc ions to the lung-to-systemic environment (Guerinot, 2000). The BBB is the interface between the systemic system and the brain, which is a critical barrier for regulating substance transport into the brain. Fig. 8 shows levels of $\mathrm{Zn}$ in the cerebellum and cortex after exposure to the control, and 5 and $10 \mathrm{mg} \mathrm{kg}^{-1} \mathrm{ZnONP}(n=5)$. The $\mathrm{Zn}$ level was higher in the cerebellum after $10 \mathrm{mg} \mathrm{kg}^{-1}$ of $\mathrm{ZnONP}$ exposure, but the level did not reach statistical significance. Also, there were no significant differences in $\mathrm{Zn}$ levels in the cerebellum or cortex after ZnONP exposure. Our results are consistent with those of previous studies (Cho et al., 2013; Adamcakova-Dodd et al., 2014), which could be due to the time point we observed after ZnONP exposure. ZnONP can cause alterations in the integrity and permeability of the BBB due to inflammation (Giovanni et al., 2015; Setyawati et al., 2015). The observation could be explained by the decrease of inflammation in brain and behavior results.

\section{Brain Histology}

Fig. 9 shows results of brain histology in the cerebellum, cortex, and hippocampus after 7-day exposure to the control, and 5 and $10 \mathrm{mg} \mathrm{kg}^{-1} \mathrm{ZnONP}$. No significant pathological changes were observed in the three regions of the brain after 


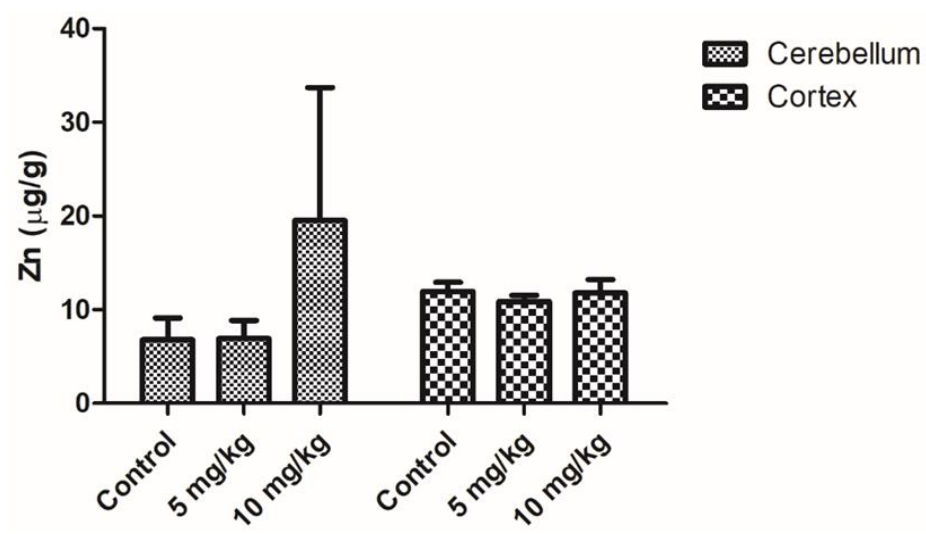

Fig. 8. Levels of $\mathrm{Zn}$ in the cerebellum and cortex after exposure to the control, and 5 and $10 \mathrm{mg} \mathrm{kg}^{-1}$ zinc oxide nanoparticles (ZnONP) $(n=5)$. There were no significant differences of the $\mathrm{Zn}$ level in the cerebellum or cortex after ZnONP exposure.
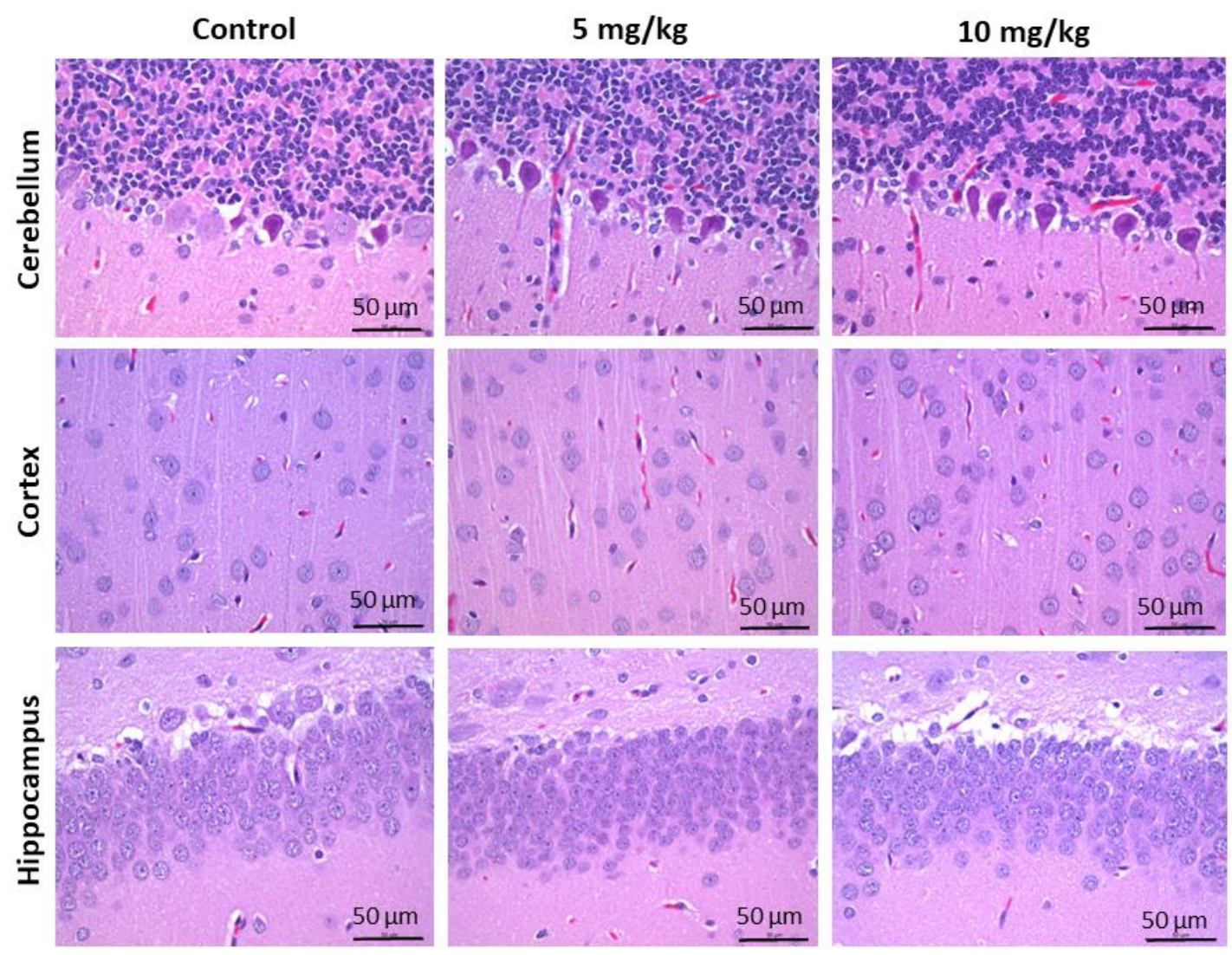

Fig. 9. H\&E staining of the cerebellum, cortex, and hippocampus after exposure to the control, and 5 and $10 \mathrm{mg} \mathrm{kg}^{-1} \mathrm{zinc}$ oxide nanoparticles (ZnONP) (400x). No significant pathological changes were observed in the three regions of the brain after ZnONP exposure. Scale bars measure $50 \mu \mathrm{m}$.

ZnONP exposure. The outbred SD rat used in the present study could lead to different results of ZnONP neurotoxicity due to its genetic variation. Therefore, evaluation of $\mathrm{ZnONP}$ neurotoxicity by more strains may be required in future works.

\section{CONCLUSIONS}

In summary, our results indicate that acute pulmonary exposure to ZnONP caused neurotoxicity in rats. We observed the occurrence of oxidative stress, microglia activation, and tau accumulation in different regions of the brain after exposure. Thus, acute exposure to $\mathrm{ZnONP}$ may also induce neurotoxicity in humans. Our findings provide clues to the effects of $\mathrm{ZnONP}$ metal fumes on neurodegenerative diseases and the underlying CNS responses.

\section{ACKNOWLEDGMENTS}

This study was funded by the Ministry of Science and 
Technology of Taiwan (103-2314-B-002-040-MY3 and 106-2314-B-002-218-MY3). Authors wholeheartedly thank Miss Yi-Syuan Lin for technical assistance during this project.

\section{DISCLAIMER}

The authors declare that they have no conflicts of interest.

\section{SUPPLEMENTARY MATERIAL}

Supplementary data associated with this article can be found in the online version at http://www.aaqr.org.

\section{REFERENCES}

Adamcakova-Dodd, A., Stebounova, L.V., Kim, J.S., Vorrink, S.U., Ault, A.P., O'Shaughnessy, P.T., Grassian, V.H. and Thorne, P.S. (2014). Toxicity assessment of zinc oxide nanoparticles using sub-acute and sub-chronic murine inhalation models. Part. Fibre Toxicol. 11: 15. https://doi.org/10.1186/1743-8977-11-15

Adamson, I.Y., Prieditis, H., Hedgecock, C. and Vincent, R. (2000). Zinc is the toxic factor in the lung response to an atmospheric particulate sample. Toxicol. Appl. Pharmacol. 166: 111-119. https://doi.org/10.1006/taap.2000.8955

Ansar, S., Abudawood, M., Hamed, S.S. and Aleem, M.M. (2017). Exposure to zinc oxide nanoparticles induces neurotoxicity and proinflammatory response: Amelioration by hesperidin. Biol. Trace Elem. Res. 175: 360-366. https://doi.org/10.1007/s12011-016-0770-8

Arakha, M., Roy, J., Nayak, P.S., Mallick, B. and Jha, S. (2017). Zinc oxide nanoparticle energy band gap reduction triggers the oxidative stress resulting into autophagymediated apoptotic cell death. Free Radical Biol. Med. 110: 42-53. https://doi.org/10.1016/j.freeradbiomed.201 7.05.015

Ashraf, J.M., Ansari, M.A., Fatma, S., Abdullah, S.M.S., Iqbal, J., Madkhali, A., Hamali, A.H., Ahmad, S., Jerah, A., Echeverria, V., Barreto, G.E. and Ashraf, G.M. (2018). Inhibiting effect of zinc oxide nanoparticles on advanced glycation products and oxidative modifications: A potential tool to counteract oxidative stress in neurodegenerative diseases. Mol. Neurobiol. 55: 74387452. https://doi.org/10.1007/s12035-018-0935-X

Bai, K.J., Chuang, K.J., Ma, C.M., Chang, T.Y. and Chuang, H.C. (2017). Human lung adenocarcinoma cells with an EGFR mutation are sensitive to non-autophagic cell death induced by zinc oxide and aluminium-doped zinc oxide nanoparticles. J. Toxicol. Sci. 42: 437-444. https://doi.org/ $10.2131 /$ jts. 42.437

Block, M.L., Zecca, L. and Hong, J.S. (2007). Microgliamediated neurotoxicity: Uncovering the molecular mechanisms. Nat. Rev. Neurosci. 8: 57-69. https://doi.org/ 10.1038/nrn2038

Bowler, R.M., Nakagawa, S., Drezgic, M., Roels, H.A., Park, R.M., Diamond, E., Mergler, D., Bouchard, M., Bowler, R.P. and Koller, W. (2007). Sequelae of fume exposure in confined space welding: A neurological and neuropsychological case series. Neurotoxicology 28: 298-311. https://doi.org/10.1016/j.neuro.2006.11.001

Cabeza, R., Ciaramelli, E., Olson, I.R. and Moscovitch, M. (2008). The parietal cortex and episodic memory: An attentional account. Nat. Rev. Neurosci. 9: 613-625. https://doi.org/10.1038/nrn2459

Calderon-Garciduenas, L., Reed, W., Maronpot, R.R., Henriquez-Roldan, C., Delgado-Chavez, R., CalderonGarciduenas, A., Dragustinovis, I., Franco-Lira, M., Aragon-Flores, M., Solt, A.C., Altenburg, M., TorresJardon, R. and Swenberg, J.A. (2004). Brain inflammation and Alzheimer's-like pathology in individuals exposed to severe air pollution. Toxicol. Pathol. 32: 650-658. https://doi.org/10.1080/01926230490520232

Carnevale, D., De Simone, R. and Minghetti, L. (2007). Microglia-neuron interaction in inflammatory and degenerative diseases: Role of cholinergic and noradrenergic systems. CNS Neurol. Disord. Drug Targets 6: 388-397. https://doi.org/10.2174/187152707783399193

Chen, B.C., Chang, Y.S., Kang, J.C., Hsu, M.J., Sheu, J.R., Chen, T.L., Teng, C.M. and Lin, C.H. (2004). Peptidoglycan induces nuclear factor-kappaB activation and cyclooxygenase- 2 expression via Ras, Raf-1, and ERK in RAW 264.7 macrophages. J. Biol. Chem. 279: 20889-20897. https://doi.org/10.1074/jbc.m311279200

Chen, T.F., Huang, R.F., Lin, S.E., Lu, J.F., Tang, M.C. and Chiu, M.J. (2010). Folic Acid potentiates the effect of memantine on spatial learning and neuronal protection in an Alzheimer's disease transgenic model. J. Alzheimers Dis. 20: 607-615. https://doi.org/10.3233/jad-2010-1396

Chesser, A.S., Pritchard, S.M. and Johnson, G.V. (2013). Tau clearance mechanisms and their possible role in the pathogenesis of Alzheimer disease. Front. Neurol. 4: 122. https://doi.org/10.3389/fneur.2013.00122

Cho, W.S., Duffin, R., Poland, C.A., Duschl, A., Oostingh, G.J., Macnee, W., Bradley, M., Megson, I.L. and Donaldson, K. (2012). Differential pro-inflammatory effects of metal oxide nanoparticles and their soluble ions in vitro and in vivo; zinc and copper nanoparticles, but not their ions, recruit eosinophils to the lungs. Nanotoxicology 6: 22-35. https://doi.org/10.3109/17435390.2011.552810 Cho, W.S., Kang, B.C., Lee, J.K., Jeong, J., Che, J.H. and Seok, S.H. (2013). Comparative absorption, distribution, and excretion of titanium dioxide and zinc oxide nanoparticles after repeated oral administration. Part. Fibre Toxicol. 10: 9. https://doi.org/10.1186/1743-8977-10-9

Chu, X.P. and Xiong, Z.G. (2012). Physiological and pathological functions of acid-sensing ion channels in the central nervous system. Curr. Drug Targets 13: 263-271. https://doi.org/10.2174/138945012799201685

Chuang, H.C., Juan, H.T., Chang, C.N., Yan, Y.H., Yuan, T.H., Wang, J.S., Chen, H.C., Hwang, Y.H., Lee, C.H. and Cheng, T.J. (2014). Cardiopulmonary toxicity of pulmonary exposure to occupationally relevant zinc oxide nanoparticles. Nanotoxicology 8: 593-604. https://doi.org/ 10.3109/17435390.2013.809809

Chuang, H.C., Chuang, K.J., Chen, J.K., Hua, H.E., Shen, Y.L., Liao, W.N., Lee, C.H., Pan, C.H., Chen, K.Y., Lee, K.Y., Hsiao, T.C. and Cheng, T.J. (2017). Pulmonary 
pathobiology induced by zinc oxide nanoparticles in mice: A 24-hour and 28-day follow-up study. Toxicol. Appl. Pharmacol. 327: 13-22. https://doi.org/10.1016/j.t aap.2017.04.018

Costa, L.G., Cole, T.B., Coburn, J., Chang, Y.C., Dao, K. and Roque, P.J. (2015). Neurotoxicity of Traffic-related air pollution. Neurotoxicology 59: 133-139. https://doi.org/ 10.1016/j.neuro.2015.11.008

da Costa Estrela, D., da Silva, W.A.M., Guimarães, A.T.B., de Oliveira Mendes, B., da Silva Castro, A.L., da Silva Torres, I.L. and Malafaia, G. (2015). Predictive behaviors for anxiety and depression in female Wistar rats subjected to cafeteria diet and stress. Physsiol. Behav. 151: 252-263. https://doi.org/10.1016/j.physbeh.2015.07.016

da Silva, W.A.M., Guimaraes, A.T.B., Montalvao, M.F., Mendes, B.O., Rodrigues, A.S.L. and Malafaia, G. (2018). The chronic exposure to abamectin causes spatial memory deficit and depressive behavior in mice. Chemosphere 194: 523-533. https://doi.org/10.1016/j.chemosphere.201 7.12.028

de Souza, J.M., Mendes, B.O., Guimaraes, A.T.B., Rodrigues, A.S.L., Chagas, T.Q., Rocha, T.L. and Malafaia, G. (2018). Zinc oxide nanoparticles in predicted environmentally relevant concentrations leading to behavioral impairments in male swiss mice. Sci. Total Environ. 613-614: 653662. https://doi.org/10.1016/j.scitotenv.2017.09.051

Dheen, S.T., Kaur, C. and Ling, E.A. (2007). Microglial activation and its implications in the brain diseases. Curr. Med. Chem. 14: 1189-1197. https://doi.org/10.2174/0929 86707780597961

Fine, J.M., Gordon, T., Chen, L.C., Kinney, P., Falcone, G. and Beckett, W.S. (1997). Metal fume fever: characterization of clinical and plasma IL-6 responses in controlled human exposures to zinc oxide fume at and below the threshold limit value. J. Occup. Environ. Med. 39: 722-726. https://doi.org/10.1097/00043764-199708 000-00006

Fine, J.M., Gordon, T., Chen, L.C., Kinney, P., Falcone, G., Sparer, J. and Beckett, W.S. (2000). Characterization of clinical tolerance to inhaled zinc oxide in naive subjects and sheet metal workers. J. Occup. Environ. Med. 42: 1085-1091. https://doi.org/10.1097/00043764-20001100 $0-00010$

Garcia, G.J. and Kimbell, J.S. (2009). Deposition of inhaled nanoparticles in the rat nasal passages: Dose to the olfactory region. Inhalation Toxicol. 21: 1165-1175. https://doi.org/10.3109/08958370902882713

Giovanni, M., Yue, J., Zhang, L., Xie, J., Ong, C.N. and Leong, D.T. (2015). Pro-inflammatory responses of RAW264.7 macrophages when treated with ultralow concentrations of silver, titanium dioxide, and zinc oxide nanoparticles. J. Hazard. Mater. 297: 146-152. https://doi.org/10.1016/j.jhazmat.2015.04.081

Gordon, T. and Fine, J.M. (1993). Metal fume fever. Occup. Med. 8: 504-517.

Grommes, J. and Soehnlein, O. (2011). Contribution of neutrophils to acute lung injury. Mol. Med. 17: 293-307. https://doi.org/10.2119/molmed.2010.00138

Guerinot, M.L. (2000). The zip family of metal transporters.
Biochim. Biophys. Acta 1465: 190-198. https://doi.org/10. 1016/s0005-2736(00)00138-3

Han, D., Tian, Y., Zhang, T., Ren, G. and Yang, Z. (2011). Nano-zinc oxide damages spatial cognition capability via over-enhanced long-term potentiation in hippocampus of Wistar rats. Int. J. Nanomed. 6: 1453-1461. https://doi.org/ 10.2147/ijn.s18507

Hickman, S.E., Kingery, N.D., Ohsumi, T.K., Borowsky, M.L., Wang, L.C., Means, T.K. and El Khoury, J. (2013). The microglial sensome revealed by direct RNA sequencing. Nat. Neurosci. 16: 1896-1905. https://doi.org/ 10.1038/nn.3554

Jayatissa, M.N., Bisgaard, C.F., West, M.J. and Wiborg, O. (2008). The number of granule cells in rat hippocampus is reduced after chronic mild stress and re-established after chronic escitalopram treatment. Neuropharmacology 54: 530-541. https://doi.org/10.1016/j.neuropharm.2007. 11.009

Johansen, T. and Lamark, T. (2011). Selective autophagy mediated by autophagic adapter proteins. Autophagy 7: 279-296. https://doi.org/10.4161/auto.7.3.14487

Jones, T., Moreno, T., BéruBé, K. and Richards, R. (2006). The physicochemical characterisation of microscopic airborne particles in south Wales: A review of the locations and methodologies. Sci. Total Environ. 360: 43-59. https://doi.org/10.1016/j.scitotenv.2005.08.055

Juan, H.T. (2011). Lung toxicity with zinc oxide nanoparticles: Study of zinc ion. Unpublished Master's Thesis, Institute of occupational medicine and industrial hygiene, National Taiwan University, Taiwan.

Kao, Y.Y., Cheng, T.J., Yang, D.M., Wang, C.T., Chiung, Y.M. and Liu, P.S. (2012). Demonstration of an olfactory bulb-brain translocation pathway for $\mathrm{ZnO}$ nanoparticles in rodent cells in vitro and in vivo. J. Mol. Neurosci. 48: 464-471. https://doi.org/10.1007/s12031-012-9756-y

Kwon, J.Y., Koedrith, P. and Seo, Y.R. (2014). Current investigations into the genotoxicity of zinc oxide and silica nanoparticles in mammalian models in vitro and in vivo: Carcinogenic/genotoxic potential, relevant mechanisms and biomarkers, artifacts, and limitations. Int. J. Nanomed. 9: 271-286. https://doi.org/10.2147/ijn.s57918

Levine, B. and Kroemer, G. (2008). Autophagy in the pathogenesis of disease. Cell 132: 27-42. https://doi.org/ 10.1016/j.cell.2007.12.018

Li, C.S., Wu, K.Y., Chang-Chien, G.P. and Chou, C.C. (2005). Analysis of oxidative DNA damage 8-hydroxy2'-deoxyguanosine as a biomarker of exposures to persistent pollutants for marine mammals. Environ. Sci. Technol. 39: 2455-2260. https://doi.org/10.1021/es0487 123

Min, S.S., Quan, H.Y., Ma, J., Han, J.S., Jeon, B.H. and Seol, G.H. (2009). Chronic brain inflammation impairs two forms of long-term potentiation in the rat hippocampal CA1 area. Neurosci. Lett. 456: 20-24. https://doi.org/10.1016/j.neulet.2009.03.079

Mushtaq, G., Khan, J.A., Joseph, E. and Kamal, M.A. (2015). Nanoparticles, neurotoxicity and neurodegenerative diseases. Curr. Drug Metab. 16: 676-684. https://doi.org/ $10.2174 / 1389200216666150812122302$ 
Oberdorster, G., Elder, A. and Rinderknecht, A. (2009). Nanoparticles and the brain: Cause for concern? $J$. Nanosci. Nanotechnol. 9: 4996-5007. https://doi.org/10. 1166/jnn.2009.gr02

Pan, C.H., Liu, W.T., Bien, M.Y., Lin, I.C., Hsiao, T.C., Ma, C.M., Lai, C.H., Chen, M.C., Chuang, K.J. and Chuang, H.C. (2014). Effects of size and surface of zinc oxide and aluminum-doped zinc oxide nanoparticles on cell viability inferred by proteomic analyses. Int. J. Nanomed. 9: 3631-3643. https://doi.org/10.2147/IJN.S66651

Pan, C.H., Chuang, K.J., Chen, J.K., Hsiao, T.C., Lai, C.H., Jones, T.P., BeruBe, K.A., Hong, G.B., Ho, K.F. and Chuang, H.C. (2015). Characterization of pulmonary protein profiles in response to zinc oxide nanoparticles in mice: A 24-hour and 28-day follow-up study. Int. J. Nanomed. 10: 4705-4716. https://doi.org/10.2147/ijn.s8 2979

Park, S.Y., Yi, E.H., Kim, Y. and Park, G. (2019). Antineuroinflammatory effects of Ephedra sinica Stapf extract-capped gold nanoparticles in microglia. Int. J. Nanomed. 14: 2861-2877. https://doi.org/10.2147/ijn.s1 95218

Perry, V.H. and Holmes, C. (2014). Microglial priming in neurodegenerative disease. Nat. Rev. Neurol. 10: 217-224.

Richards, R.J., Atkins, J., Marrs, T.C., Brown, R.F. and Masek, L. (1989). The biochemical and pathological changes produced by the intratracheal instillation of certain components of zinc-hexachloroethane smoke. Toxicology 54: 79-88. https://doi.org/10.1016/0300-483x (89)90080-2

Rovira, E., Cuadras, A., Aguilar, X., Esteban, L., BorrasSantos, A., Zock, J.P. and Sunyer, J. (2014). Asthma, respiratory symptoms and lung function in children living near a petrochemical site. Environ. Res. 133: 156-163. https://doi.org/10.1016/j.envres.2014.05.022

Samardzic, J., Savic, K., Stefanovic, N., Matunovic, R., Baltezarevic, D., Obradovic, M., Jancic, J., Opric, D. and Obradovic, D. (2013). Anxiolytic and antidepressant effect of zinc on rats and its impact on general behavioural parameters. Vojnosanit Pregl. 70: 391-395. https://doi.org/ 10.2298/vsp111129036s

Serrano-Pozo, A., Frosch, M.P., Masliah, E. and Hyman, B.T. (2011). Neuropathological alterations in alzheimer disease. Cold Spring Harb Perspect. Med. 1: a006189. https://doi.org/10.1101/cshperspect.a006189

Setyawati, M.I., Tay, C.Y. and Leong, D.T. (2015). Mechanistic investigation of the biological effects of $\mathrm{SiO}_{2}, \mathrm{TiO}_{2}$, and $\mathrm{ZnO}$ nanoparticles on intestinal cells. Small 11: 3458-3468. https://doi.org/10.1002/smll.20140 3232

Shao, L., Hou, C., Geng, C., Liu, J., Hu, Y., Wang, J., Jones, T., Zhao, C. and BéruBé, K. (2016). The oxidative potential of $\mathrm{PM}_{10}$ from coal, briquettes and wood charcoal burnt in an experimental domestic stove. Atmos. Environ. 127: 372 381. https://doi.org/10.1016/j.atmosenv.2015.12.007

Shao, L., Hu, Y., Shen, R., Schafer, K., Wang, J., Wang, J., Schnelle-Kreis, J., Zimmermann, R., BeruBe, K. and Suppan, P. (2017). Seasonal variation of particle-induced oxidative potential of airborne particulate matter in
Beijing. Sci. Total Environ. 579: 1152-1160. https://doi.org/ 10.1016/j.scitotenv.2016.11.094

Sharma, A.K., Singh, V., Gera, R., Purohit, M.P. and Ghosh, D. (2017). Zinc oxide nanoparticle induces microglial death by NADPH-oxidase-independent reactive oxygen species as well as energy depletion. Mol. Neurobiol. 54: 6273-6286. https://doi.org/10.1007/s12035-016-0133-7

Sharma, H.S. and Sharma, A. (2012). Neurotoxicity of engineered nanoparticles from metals. CNS Neurol. Disord. Drug Targets 11: 65-80. https://doi.org/10.2174/ 187152712799960817

Shim, K.H., Hulme, J., Maeng, E.H., Kim, M.K. and An, S.S. (2014). Analysis of zinc oxide nanoparticles binding proteins in rat blood and brain homogenate. Int. J. Nanomed. 9: 217-224. https://doi.org/10.2147/ijn.s58204

Sruthi, S. and Mohanan, P.V. (2015). Investigation on cellular interactions of astrocytes with zinc oxide nanoparticles using rat C6 cell lines. Colloids Surf., B 133: 1-11. https://doi.org/10.1016/j.colsurfb.2015.05.041

Tang, Y. and Le, W. (2016). Differential roles of M1 and M2 microglia in neurodegenerative diseases. Mol. Neurobiol. 53: 1181-1194. https://doi.org/10.1007/s12035-014-9070-5

Tian, L., Lin, B., Wu, L., Li, K., Liu, H., Yan, J., Liu, X. and $\mathrm{Xi}, \mathrm{Z}$. (2015). Neurotoxicity induced by zinc oxide nanoparticles: Age-related differences and interaction. Sci. Rep. 5: 16117. https://doi.org/10.1038/srep16117

Torabi, M., Kesmati, M., Harooni, H.E. and Varzi, H.N. (2013). Effects of nano and conventional Zinc Oxide on anxiety-like behavior in male rats. Indian J. Pharmacol. 45: 508-512. https://doi.org/10.4103/0253-7613.117784

Uttara, B., Singh, A.V., Zamboni, P. and Mahajan, R.T. (2009). Oxidative stress and neurodegenerative diseases: A review of upstream and downstream antioxidant therapeutic options. Curr. Neuropharmacol. 7: 65-74. https://doi.org/10.2174/157015909787602823

Vegeto, E., Benedusi, V. and Maggi, A. (2008). Estrogen anti-inflammatory activity in brain: A therapeutic opportunity for menopause and neurodegenerative diseases. Front. Neuroendocrinol. 29: 507-519. https://doi.org/10. 1016/j.yfrne.2008.04.001

Vietti, G., Ibouraadaten, S., Palmai-Pallag, M., Yakoub, Y., Bailly, C., Fenoglio, I., Marbaix, E., Lison, D. and van den Brule, S. (2013). Towards predicting the lung fibrogenic activity of nanomaterials: Experimental validation of an in vitro fibroblast proliferation assay. Part. Fibre Toxicol. 10: 52. https://doi.org/10.1186/1743-8977-10-52

Villa, A., Vegeto, E., Poletti, A. and Maggi, A. (2016). Estrogens, neuroinflammation, and neurodegeneration. Endocr. Rev. 37: 372-402. https://doi.org/10.1210/er.201 6-1007

Walf, A.A. and Frye, C.A. (2007). The use of the elevated plus maze as an assay of anxiety-related behavior in rodents. Nat. Protoc. 2: 322-328. https://doi.org/10.1038/ nprot. 2007.44

Wolf, U., Rapoport, M.J. and Schweizer, T.A. (2009). Evaluating the affective component of the cerebellar cognitive affective syndrome. J. Neuropsychiatry Clin. Neurosci. 21: 245-253. https://doi.org/10.1176/jnp.2009. 21.3.245 
Wu, C., Chen, S.T., Peng, K.H., Cheng, T.J. and Wu, K.Y. (2016). Concurrent quantification of multiple biomarkers indicative of oxidative stress status using liquid chromatography-tandem mass spectrometry. Anal. Biochem. 512: 26-35. https://doi.org/10.1016/j.ab.2016.07.030

Xiao, Z., Shao, L., Zhang, N., Wang, J. and Wang, J. (2013). Heavy metal compositions and bioreactivity of airborne $\mathrm{PM}_{10}$ in a valley-shaped city in northwestern China. Aerosol Air Qual. Res. 13: 1116-1125. https://doi.org/10. 4209/aaqr.2012.10.0287

Xie, Y., Wang, Y., Zhang, T., Ren, G. and Yang, Z. (2012). Effects of nanoparticle zinc oxide on spatial cognition and synaptic plasticity in mice with depressive-like behaviors. J. Biomed. Sci. 19: 14. https://doi.org/10.1186/1423-012719-14
Yu, K.N., Yoon, T.J., Minai-Tehrani, A., Kim, J.E., Park, S.J., Jeong, M.S., Ha, S.W., Lee, J.K., Kim, J.S. and Cho, M.H. (2013). Zinc oxide nanoparticle induced autophagic cell death and mitochondrial damage via reactive oxygen species generation. Toxicol. in Vitro 27: 1187-1195. https://doi.org/10.1016/j.tiv.2013.02.010

Zhao, J., Xu, L., Zhang, T., Ren, G. and Yang, Z. (2009). Influences of nanoparticle zinc oxide on acutely isolated rat hippocampal CA3 pyramidal neurons. Neurotoxicology 30: 220-230. https://doi.org/10.1016/j.neuro.2008.12.005

Received for review, October 21, 2019

Revised, January 12, 2020

Accepted, February 13, 2020 